DOI: https://doi.org/10.32839/2304-5809/2020-12-88-12

УДК 159.9

Шапошников С.H.

ОО «Движение Энодрайв»;

Международная ассоциация фрасилитаторов (IAF);

Drum Circle Facilitators Guild (DCFG)

\title{
КЛЮЧЕВЫЕ КОМПЕТЕНЦИИ ФАСИЛИТАТОРА ДЛЯ РАБОТЫ В МЕТОДЕ «БАРАБАННАЯ ФАСИЛИТАЦИЯ»
}

Аннотация. В статье дано описание ключевых компетенций фасилитатора в методе «барабанная фаси-
литация». Компетенции описанные в данной статье были выделены в результате проведения учебного
курса «Барабанная фасилитация для трансформации конфликтов» и подготовки двух групп фасилита-
торов, испольующих данный метод для фасилитации конфликтов в школьной среде. Обучающая про-
грамма подготовки фасилитаторов рассчитана на один календарный год и включает в себя 10 тренин-
гов семинаров, продолжительностью 16 академических часов каждый. Во время обучения каждый из
участников программы подготовил и запустил собственный проект, направленный на трансформацию
конфликтов в школьной среде, методом барабанной фасилитации. В процессе реализации собственных
проектов, каждый из участников получал супервизию по процессу внедрения проектов и возможность
корректировки реализуемого проекта. Итогом реализации обучающего проекта стало подготовка двух
групп фасилитаторов в технике барабанная фасилитация и запуск собственных проектов, связанных с
трансформацией конфликтов методом барабанная фасилитация.

Ключевые слова: барабанный круг, барабанная фасилитация, компетенции фасилитатора, безоценочность, эмоциональный интеллект, коммуникация, артистизм, креативность, ритмичность, внимание, эмоциональная грамотность, осознанность.

Shaposhnikov Stanislav

NGO "Ethnodrive Movement"; International Association of Facilitators (IAF); Drum Circle Facilitators Guild (DCFG)

\section{KEY COMPETENCIES OF A FACILITATOR TO WORK IN THE METHOD «DRUM FACILITATION»}

Summary. The article describes the key competencies of the facilitator in the "drum facilitation" method. The competencies described in this article were high-lighted as a result of the training course "Drum Facilitation for Conflict Transfor-mation" and the training of two groups of facilitators using this method to facilitate conflict in the school environment. The training program for the preparation of facilitators is designed for one calendar year and includes 10 training seminars, each lasting 16 academic hours. During the training, each of the program participants prepared and launched their own project aimed at transforming conflicts in the school environment, using the drum facilitation method. In the process of implementing their own projects, each of the participants received supervision on the process of project implementation and the possibility of adjusting the ongoing project. The article describes the key competencies that are necessary for the successful and effective work of the facilitator in this approach. These competencies are as follows: valuelessness, awareness, emotional literacy, communication, attention, artistry, creativity, rhythm. For each competence, its definition is given in the author's interpretation and the manifestation of this competence in the work of the facilitator. Its significance and value are shown. The article defines the terms "emotional literacy", "circular communication model", "three-position description model". All of the above competencies are distributed in three areas: Related to the inner world and the emotional sphere: "Non-judgmental", "Awareness", "Emotional literacy". Interaction-related: "Communication", "Attention". Associated with creative expression: Artistic, Creativity, Rhythm. The result of the implementation of the training project was the training of two groups of facilitators in the drum facilitation technique and the launch of their own projects related to the transformation of conflicts using the drum facilitation method. As a result of using this method, the school atmosphere has improved, the level of aggression has decreased, and cases of bullying have practically disappeared.

Keywords: drum circle, drum facilitation, facilitator's competence, non-judgmental, emotional intelligence, communication, artistry, creativity, rhythm, attention, emotional literacy, awareness.

Постановка проблемы. На сегодняш1 ний момент существует множество описанных продрессиональных компетенций фрасилитатора. Но в рамках разрабатываемой автором концепции «барабанная фрасилитация» не существует специфически обусловленных компетенций, связанных непосредственно с описанным методом «барабанная фасилитация». В результате проведенного учебно-практического проекта «Творцы согласия» автором, были выделены и описаны профрессиональные компетенции, непосредственно связанные с данным методом.

Анализ последних исследований. Существуют разработанные модели про-фрессиональных компетенций фрасилитатора например модель компетенций IAF (Международной Ассоциации Фасилитаторов) и дальнейшие разработки на основе базовой модели $[1 ; 2 ; 3]$. В этой модели описаны 6 групп компетенций: построение отношений сотрудничества с клиентами, планирование подходящего группового процесса, создание 
и поддержание включающей среды для совместных действий группы, направление группы к достижению необходимых и ценных результатов, формирование и совершенствование профрессиональных знаний, позитивность в профессиональных установках и отношении.

Также существуют модели профессиональных компетенции выделенных для арт профессий, так например Competencies in art education [4]. Сюда входят: «творческие способности», «способность к критическому размышлению», «способность к росту и инновациям», «организационная способность», «коммуникативная способность», «внешняя осведомленность», «способность к сотрудничеству».

Также выделены и описаны компетенции для ведущего барабанных кругов .

Drum Circle Facilitation Skills [5]. В этой модели придается большое значение музыкальным навыкам, таким как: «умение держать ритм ровным», «умение играть основные звуки на нескольких барабанах и перкуссионных инструментах», "умение демонстрировать и обучать основным навыкам игры на барабанах», "умение поддерживать устойчивый ритм при музыкальной игре», «умение постепенно увеличивать, замедлять, увеличивать и уменьшать громкость музыки».

Выделение нерешенных ранее частей общей проблемы. Таким образом на сегодняшний день, существуют модели профрессиональных компетенций, разработанные для разных областей фрасилитации. Но так как метод барабанная фасилитация обьединяет в себе несколько направлений, то модели профессиональных компетенций барабанного фрасилитатора не были выделены в отдельную тему. Автор восполняет этот пробел, выделяя специфичные профрессиональные компетенции, для фрасилитатора, работающего в методе «барабанная фрасилитация».

Главная цель данной статьи - дать описание профессиональных компетенций фрасилитатора, использующего метод «барабанная фрасилитация» в своей работе.

Метод «барабанная фосилитация», разработан Станиславом Шапошниковым, заключается в применении ритмических и звуковых инструментов для активизации групповой динамики и трансформации конфрликтов [6; 7].

Предлагаю рассмотреть компетенции ведущего группы по данному методу - барабанного фрасилитатора.

Ключевыми компетенциями барабанного фрасилитатора я обозначил следующие:

- безоценочность;

- осознанность;

- эмоциональная грамотность;

- коммуникативность;

- внимание;

- артистичность;

- креативность;

- ритмичность;

Теперь остановимся более подробно на каждой из обозначенных компетенций, применительно к методу барабанная фрасилитация.

Безоценочность - свойство личности воспринимать окружающие явления без присвоения характеристик в категориях "хорошо» или «плохо», т.е. находясь в процессе «чистого» наблюдения и восприятии явления. Это свойство, связано с умением быть осознанным и умением отслеживать собственные желания, чтобы дать оценку происходящему и умением отпускать эти желания.

Безоценочность важна в практике фрасилитатора, т.к. дает возможность воспринимать группу и групповые френомены в полевом взаимодействии, накапливая материал для понимания, состояния группы, и возможных вариантов действий. Вполне возможно, что в дальнейшем фpaсилитатору понадобится совершить оценку, для принятия решений о дальнейшей стратегии поведения. Но весь вопрос в том, чтобы не давать преждевременную оценку, чтобы суметь накопить достаточно информации, и чтобы преждевременная оценка не повлияла на стратегию фрасилитции.

Умение держать паузу и не давать оценку, тесно связано с таким навыком как осознанность.

Осознанность - навык или свойство личности при котором происходит дистанциирование от мыслительного внутреннего диалога, в позицию внутреннего наблюдателя. Такая дистанция приводит к развитию умения наблюдать за своими внутренними проявлениями. При развитии навыка осознанности, происходит увеличение дистанции между переживаемыми внутренними событиями: мыслями, ощущениями, эмоциями и реакцией на них. В этом случае наблюдатель, может выбирать планируемую реакцию, а может не реагировать вообще.

Соответственно, если мы возьмем оценку как реакцию на наблюдаемое явление, то при развитии навыка осознанности, эта реакция также отодвигается во времени и у наблюдателя появляется больше свободы для действий и больше возможностей для осознанного выбора.

Следующим навыком или компетенцией барабанного фрасилитатора является эмоциональная грамотность.

Этот термин был впервые использован Клодом Штайнером [8], который говорит, что: «элоииональная гралотность состоит из "способности понилать ваши элоции, уления слушать других и сопереживать их элоииял, а такюе уления эбббективно выражать элоиии».

Таким образом при развитии осознанности и безоценочности, барабанный фрасилитатор может более глубже наблюдать свои внутренние чувства, эмощии и ощущения, которые возникают во время работы, и результаты этого наблюдения становятся инструментом для более тонкой настройки на эмоциональный фон группы. Когда мы обучаемся внутреннему наблюдению, то можем более четко отслеживать в какие моменты мы испытываем внутренние эмоциональные всплески, когда происходит изменение ощущений и чувств, одновременно соотнося их с внешними проявлениями групповой динамики, тем самым анализируя и понимая, что происходит с группой в целом.

Таким образом три навыка: безоценочность, осознанность и эмоциональная грамотность дают нам мошный инструмент для работы с группой, через понимание себя и своих внутренних проявлений.

Коммуникативность - это способность четко выражать свои мысли, для передачи собеседнику, слышать обратную связь в процессе коммуникации, совершать корректировку своей речи 
для обеспечения полного понимания сказанного собеседником и в свою очередь понимать полностью высказывания собеседника и сообщать ему об этом. Коммуникативность в аспекте взаимодействия с группой, будет проявляться в умении выражать свои мысли так, чтобы это было понятно всей группе, ориентируясь на самого непонимающего участника группы, получая обратную связь о понимании и корректировки своей речи для наиболее полного понимания и получения нужного действия результата от группы.

В процессе коммуникации выделяют несколько основных этапов: кодирование - сообщение - декодирование - интерпретация - кодирование - сообщение - декодирование интерпретация по теории «Циркулярная модель коммуникации» Осгуда - Шрамма [9].

В соответствии с этим подходом, коммуникация это двусторонний процесс передачи информации от фасилитатора группе и от группы фрасилитатору.

Вначале фрасилитатор кодирует, т.е. подготавливает для передачи свое сообение, переводит его на язык, понятный группе, затем происходит сообщение, сам процесс передачи информации. Затем происходит принятие и декодирование сообщения группой, т.е. перевод на понятный язык. Дальше интерпретация, т.е. понимание смысла сообщения, переданного фрасилитатором. Дальше происходит результат - это действие группы, одновременно для фрасилитатора, это действие является проявлением уровня понимания, того что он сообщил и возможность откорректировать свое сообщение. Это процесс повторяется циклично, до получения желаемого результата.

В ситуации барабанной фрасилитации, языком коммуникации часто является ритмическое сообщение. Фасилитатор показывает определенный ритм группе, и группа его повторяет. Фасилитатор слышит на каком уровне происходит понимание, буквально удалось ли группе повторить заданный ритм. Если есть сложности, то он может повторить ритм еще раз, может вернуться на более простой ритм, повторение которого не вызывает сложностей, может подойти к тому, участнику, которому наиболее сложно повторить данный ритм и лично показать ему как правильно сыграть.

Таким образом коммуникативный акт в барабанной фрасилитации это передача ритма от фрасилитатору группе и обратно, или от участников друг другу.

Следующая компетенция барабанного фрасилитатора это внимание.

Внимание - это избирательная направленность на тот или иной объект и сосредоточенность на нем, углубленность в направленную на объект познавательную деятельность [10].

Таким образом внимание в практике фрасилитатора, внимание - это избирательная направленность на различные объекты и феномены, возникающие в процессе групповой работы.

При этом можно говорить о такой характеристике внимания как объём, т.е. количество объектов на котором фрасилитатор может сосредоточится.

В процессе барабанной фрасилитации таких объектов может быть большое количество: это и участники, и ритмические фригуры, и собственная игра, и внутренние переживания.
Поэтому фрасилитатору важно уметь выделять ключевые объекты для фиксирования внимания на нем.

Я предлагаю использовать методику трехпозиционного описания, взятую из теории НЛП, авторства Вирджинии Сатир [11].

Согласно этой модели, у фрасилитатора есть три области для направления своего внимания.

Первая область - «я сам» - это область которая связана с осознанностью и позволяет отслеживать свои переживания, мысли и чувства в данный момент времени.

Вторая область - «я другой» - это область внимания, направленная на другого человека и позволяет предполагать, на основе считывания невербальной и вербальной коммуникации, какие чувства, эмощии и ощущения испытывает другой человек.

Третья область - это «наблюдатель» направлена на сам процесс коммуникации, который происходит между фасилитатором и группой. Здесь фрасилитатор получает ответ на вопрос: «что сейчас происходит в нашем взаимодействии?».

Таким образом развитие компетенции «внимание» подразумевает в данном случае умение удерживать свое внимание одновременно на всех трех областях и умение динамично фокусироваться на любой из них, с более крупной детализацией проявляющихся феноменов.

Также фрасилитатору необходимо учитывать очень сильный информационный шум, а именно громкие звуки барабанного боя, рассогласованность игры, приводящая к какофонии, рассеянность внимания участников, особенно, если это детский возраст. И в этом случае важно умение фрасилитатора удерживать собственное внимание и помнить о целях и задачах фрасилитации. Это проявление такого качества, как сосредоточенность.

Также со вниманием связано такое качество, как переключаемость. Это характеристика обозначает возможность быстрого перенаправления внимания на различные объекты как внутри, так и снаружи. Таким образом позволяя фрасилитатору быстро реагировать на динамику групшы и менять тактику и стратегию проведения фрасилитаџии.

Теперь обозначу компетенции, которые связаны с артистичностью фасилитатора, его умением быть в центре внимания и наполнять атмосферу «фаном» и энергией.

Сюда относятся такие компетенции как: артистичность, креативность, ритмичность.

Разберем подробно каждую из этих компетенщий.

Артистичность, харизма, обаяние - это умение увлекать других своим поведением, проявлением своих эмоций, своими идеями. «Заражать» и мотивировать зрителей и делать их участниками совместного действа.

Для того, чтобы артистичность максимально проявилась, необходимо научиться отпускать себя, свои эмоции, проявлять свое естественное поведение. Позволять своим чувствам проявляться.

Это отражается в невербальном языке: мимика, поза, жесты. Все это действует на окружающих, то насколько фрасилитатор может выражать свои эмоции через тело, зависит уровень его артистизма и харизмы.

Креативность понимается как общая способность к творчеству. Креативность (от лат. 
creatio - созидание) - это способность человека порождать необычные идеи, находить оригинальные решения, отклоняться от традиционных схем мышления [12]. Барабанный фрасилитатор - это человек, который все время проводит в творческом взаимодействии с группой.

Динамика группы включает творческую активность в том, как комбинировать различные инструменты для открытия группы, для развития коммуникации, преодоления напряжения, для активизации творчества.

Новые идеи, которые возникают у фрасилитатоpa, его инсайты, которые происходят в процессе фрасилитащии, могут и должны быть включены в поле фасилитации и предъявлены участникам как новые вызовы и грани процесса взаимодействия.

Таким образом творчество является важной компетенцией фрасилитатора, позволяющая быть открытой к новым идеям, как со своей стороны, так и со стороны группы, поощрение к совместному творчеству и рождению новых смыслов.

Ритмичность - способность чувствовать свой собственный ритм и ритм группы. Доверять ему и следовать за ним.

Ритмичность это не что-то приобретенное, нет наоборот, это наше врожденное качество и свойство. Но в процессе взросления, мы можем перестать обращать внимание на внутренний ритм и стать более социальными.

Внутри нас есть много биологически и фризиологически обусловленных ритмов. Например, ритм сердца, ритм дыхания, ритм сна бодрствования.

Bce это дает определенную динамику внутреннего пространства, субъективно отображаемую в наших переживаниях своего ритма.

Если развивать осознанность и интуицию, научиться слушать свое тело, то можно почувствовать и свой внутренний ритм, он может проявится в желании танцевать под понравившуюся музыку, или в желании побарабанить в такт звучанию ритмичной мелодии. И слушая себя, мы можем идти за проявлениями своим ритмом, открывая себя и открывая других.

Поэтому не важно для барабанного фасилитатора умение играть на барабанах, это скорее вторичный навык, «жесткие» скиллы. Если фра- силитатор слышит свой ритм, умеет идти за ним, то и барабанный ритм возникнет сам по себе и зажжет других, отзываясь внутри и открывая их внутренний ритм.

Выводы. В данной статье описаны специфичные профрессиональные компетенции фрасилитатора, работающего в методе «барабанная фрасилитация».

Все описанные компетенции, были разделены по трем ключевым группам:

1. Связанные с внутренним когнитивным миром и эмоциональной сферой фрасилитатора.

В этой группе находятся следующие компетенции: «Безоценочность», «Осознанность», «Эмоциональная грамотность».

2. Связанные со взаимодействием между фрасилитатором и группой.

В этой группе находятся следующие компетенции: «Коммуникативность», «Внимание».

3. Связанные с творческим выражением фрасилитатора:

В этой группе находятся следующие компетенции: «Артистичность», «Креативность», «Ритмичность».

По каждой компетенции было дано определение и способы проявления компетенции в работе фасилитатора. Обозначены умения и навыки, вхо-дящие в состав компетенции.

Таким образом выделенные компетенции важны для обозначения уникальности работы фрасилитатора, применяющего методы барабанной фрасилитации в своей работе. Они позволяют более точно и конкретно подойти к процессу подготовки и развития барабанного фасилитатора. Использовать узконаправленные инструменты обучения. А именно обучение в области коммуникативных навыков, в области самоосознанности и эмоционального интеллекта, а также в области артистизма и развития харизмы.

Также выделенные компетенции, позволяют более точно и взвешенно проводить оценку работы фрасилитатора. Делать её узконаправленной именно на данные компетенции, степень их проявления, что позволяет использовать результаты оценки для дальнейшего развития и повышения уровня квалификации фрасилитатора.

\section{Список литературы:}

1. IAF Core Competencies. URL: https://www.iaf-world.org/site/professional/core-competencies (дата обращения: 29.12.2020)

2. Elena Aguilar. Facilitator Core Competencies, The Art of Coaching Teams: Building Resilient Communities that Transform Schools. Jossey-Bass, 2016, p. 5.

3. ToP Facilitation Competencies. URL: http://www.ica-international.org/top-facilitation/top-facilitation-competencies/ (дата обращения: 29.12.2020).

4. Competenties in kunstonderwijs. URL: https://www.kabk.nl/en/studying-at-kabk/competencies (дата обращения: 29.12.2020).

5. Kalani Дас. URL: https://www.x8drums.com/blog/community-drumming-facilitation-essential-skills-for-success/ (дата обращения: 29.12.2020).

6. Шапошников С.Н. Аспекты применения метода «барабанная фрасилитация» для трансформации конфликтов в школьной атмосфере / Педагогика и психология в современном мире: теоретические и практические исследования : сб. ст. по материалам XLII Международной научно-практической конференции «Педагогика и психология в современном мире: теоретические и практические исследования». № 12(42). Москва : Изд. «Интернаука», 2020. С. 35-40.

7. Кочерга Є., Лук'янченко С., Шапошніков С., Кандибур Р., Хлистік А. Ритмічне колоєднання - унікальні практичні інструменти роботи в згуртуванні освітніх спільнот. Вища Освіта Украӥни. Теоретичний та науково-методичний часопис. 2020. № 2(77). С. 52-58.

8. Steiner C. with Perry P. (1997). Achieving Emotional Literacy. London : Bloomsbury, p. 288.

9. Schramm W. How Communication Works // Process and Effects of Mass Communication. Urbana : University of Illinois Press, 1954, p. 997. 
10. Рубинштейн С.Л., Брушлинский А.В., Абульханова-Славская К.А. Основы общей психологии. СанктПетербург : Издательство «Питер», 2000. С. 718.

11. Сатир В., Бендлер Р., Гриндер Д. Семейная терапия и НЛП. Москва : Институт общегуманитарных исследований, 2000. С. 188.

12. Ильин Е.П. Психология творчества, креативности, одаренности. Санкт-Петербург : Питер, 2009. С. 448.

\section{References:}

1. IAF Core Competencies. URL: https://www.iaf-world.org/site/professional/core-competencies (accessed: 12.29.2020).

2. Elena Aguilar (2016). Facilitator Core Competencies, The Art of Coaching Teams: Building Resilient Communities that Transform Schools. Jossey-Bass, p. 5.

3. ToP Facilitation Competencies. URL: http://www.ica-international.org/top-facilitation/top-facilitation-competencies/ (accessed: 12.29.2020).

4. Competenties in kunstonderwijs. URL: https://www.kabk.nl/en/studying-at-kabk/competencies (accessed: 12.29.2020).

5. Kalani Дac. URL: https://www.x8drums.com/blog/community-drumming-facilitation-essential-skills-for-success/ (accessed: 12.29.2020).

6. Shaposhnikov S.N. (2020). Aspekty primeneniia metoda "barabannaia fasilitatsiia:" dlia transformatsii konfliktov v shkolnoi atmosphere / Pedagogika i psikhologiia v sovremennom mire: teoreticheskie i prakticheskie issledovaniia: sb. st. po materialam XLII Mezhdunarodnoi nauchno-prakticheskoi konferentsii "Pedagogika i psikhologiia v sovremennom mire teoreticheskie i prakticheskie issledovaniia", no. 12(42). Moskva: Izd. "Internauka".

7. Kocherha Ye., Lukianchenko S., Shaposhnikov S.,Kandybur R., Khlystik A. (2020). Rytmichne koloiednannia unikalni praktytchni instrumenty roboty vzghurtuvanni osvitnikh spilnot. Vyshcha Osvita Ukrainy Teoretychnyi ta naukovo-metodychnyi chasopys, no. 2(77), pp. 52-58.

8. Steiner C. with Perry P. (1997). Achieving Emotional Literacy. London: Bloomsbury, p. 288.

9. Schramm W. (1954). How Communication Works // Process and Effects of Mass Communication. Urbana: University of Illinois Press, p. 997.

10. Rubinshtein S.L., Brushlinskii A.V., Abulkhanova-Slavskaia K.A. (2000). Osnovy obshchei psikhologii. SanktPeterburg: Izdatelstvo "Piter", p. 718.

11. Satyr V., Bandler R., Grinder D. (2000). Semeinaia terapiia i NLP. Moskva: Institut obshchegumanitarnykh issledovanii, p. 188.

12. Ilyin E.P. (2009). Psikhologiia tvorchestva kreativnosti odarennosti. Sankt-Peterburg: Piter, p. 448. 